\title{
ELECTROCHEMICAL RESPONSE OF CO-PRECIPITATED AND LAYER-BY-LAYER PRECIPITATED HYDROUS NICKEL HYDROXIDE AND HYDROUS COBALT HYDROXIDE ON PLATINUM IN ALKALINE SOLUTIONS
}

\author{
M.E. FOLQUER *, J.R. VILCHE and A.J. ARVIAA \\ Instituto de Investigaciones Fisicoquímicas Teóricas y Aplicadas, INIFTA, C.C. I6, Suc. 4, 1900 La Plata \\ (Argentina)
}

(Received 2nd November 1983; in revised form 21st February 1984)

\begin{abstract}
The voltammetric and open circuit responses of $\mathrm{Pt} /$ co-precipitated hydrous nickel and cobalt hydroxides (mixed hydroxide)/electrolyte, Pt/hydrous nickel hydroxide/hydrous cobalt hydroxide (alternate hydroxide)/electrolyte, and $\mathrm{Pt} /$ hydrous cobalt hydroxide/hydrous nickel hydroxide (alternate hydroxide)/electrolyte are investigated in $0.1 \mathrm{M} \mathrm{KOH}$ at $25^{\circ} \mathrm{C}$. The co-precipitated hydroxide electrode shows that the presence of hydrous cobalt hydroxide increases the reversibility of the $\mathrm{Ni}$ (II)/Ni(III) redox reaction. This behaviour is interpreted in terms of a catalytic effect of the $\mathrm{Co}$ (II)/Co(III) reaction on the $\mathrm{Ni}(\mathrm{II}) / \mathrm{Ni}(\mathrm{III})$ reaction through hydroxide ions inserted into the metal hydroxide layer.
\end{abstract}

\section{INTRODUCTION}

Hydrous metal hydroxide and oxide systems play a very important role in defining the passivation and corrosion of metals in aqueous solutions [1-18] and, due to their high activity, satisfactory thermodynamic stability, availability and cheapness, they are attractive for the development of efficient electrodes for batteries and electrolyzers [19-27]. As far as the first matter is concerned, perhaps the most important example is the increase in the number of charging-discharging cycles of hydrous nickel hydroxide electrodes in alkaline solutions produced by the incorporation of hydrous cobaltous hydroxide [27-39]. The latter apparently hinders the ordering of the hydrous nickel hydroxide lattice which causes a decrease in the activity of hydrous nickel hydroxide electrodes [27-32,37-39]. On the other hand, the design of spinel-type oxide electrodes for electrolyzers furnishes an example of modifying the electrocatalytic properties of a single metal oxide (nickel oxide) by incorporation of a second oxide (cobalt oxide) $[23,24]$. In this case, the kinetics and mechanism of the different electrochemical reactions changc according to the

\footnotetext{
* Present address: Instituto de Química Física, Universidad Nacional de Tucumán, 4000 Tucumán, Argentina.
} 
structural properties of the electrocatalyst. In this way it is also possible to produce either activation or inhibition of various electrochemical reactions when metal hydroxide electrodes of different structures are employed. Thus, the addition of hydrous cobaltous hydroxide to hydrous nickel hydroxide electrodes increases the overpotential of the oxygen evolution reaction [34].

Despite the fact that electrodes made of mixtures of either hydrous metal hydroxides or oxides are already employed as electrocatalysts in different electrochemical devices $[23,24,40,41]$, there are no final answers either to the question of the mechanism of activation and deactivation of the reactant species or to the question of how to control the reactivity of the electrocatalysts. In this respect, recent results indicate that the electrocatalytic activity of hydrous metal hydroxide electrodes depends to a large extent on the history of the base material, including proper ageing and the insertion of different ionic and non-ionic species into the hydrous metal hydroxide layers [42-44].

The present paper deals with the electrochemical behaviour of platinum substrate electrodes covered by a layer containing hoth hydrous nickel and cobalt hydroxides either as a co-precipitated (mixed hydroxide) layer or as alternate oxide layers. The influence of the hydroxide layer structure of the various kinds of electrodes on the charging/discharging processes is investigated in the absence of base metal electrodissolution. The results throw further light on the mechanism of the charging/discharging processes, particularly in relation to the role played by $\mathrm{OH}^{-}$ion insertion into the hydrous nickel hydroxide lattice.

\section{EXPERIMENTAL}

The experimental set-up was the same as already described in a previous publication [38]. The working electrodes consisted of layers of chemically precipitated metal hydroxides on a platinum ("Specpure", Johnson Matthey Chemicals Ltd.) wire $\left(0.5 \mathrm{~mm}\right.$ diameter, $0.2 \mathrm{~cm}^{2}$ apparent area). The platinum substrate was cleaned by a 15-min immersion in $1: 1 \mathrm{H}_{2} \mathrm{SO}_{4}+\mathrm{HNO}_{3}$ mixture followed by repeated rinsing in triply distilled water. The procedure for the preparation of the metal hydroxide layer on the platinum electrode surface depended on whether a co-precipitated hydrous nickel and cobalt layer (procedure 1) or an alternate oxide layer of cobalt and nickel hydroxides (procedure 2) was made. According to procedure 1 , the electrode was obtained by co-precipitation from alternate immersions in $5 \times 10^{-4} M \mathrm{NiSO}_{4}+X M \mathrm{CoSO}_{4}$ solution $\left(0 \leqslant X \leqslant 5 \times 10^{-4}\right)$ and in $0.1 \mathrm{M}$ $\mathrm{KOH}$ solution. The immersion time in each solution was fixed at $5 \mathrm{~s}$ and the number of alternate immersions $\left(n_{0}\right)$ was varied from 5 to 100 . Procedure 2 involved the following two-stage precipitation: the electrode preparation consisted of $n_{1}$ alternate immersions in $Y_{1} M \mathrm{NiSO}_{4}+X_{1} M \mathrm{CoSO}_{4}$ solution $\left(0 \leqslant Y_{1} \leqslant 5 \times 10^{-4} ; 0 \leqslant X_{1} \leqslant\right.$ $10^{-3}$ ) and in $0.1 \mathrm{M} \mathrm{KOH}$ solution followed by $n_{2}$ alternate immersions in $Y_{2} M$ $\mathrm{NiSO}_{4}+X_{2} M \mathrm{CoSO}_{4}$ solution $\left(0 \leqslant Y_{2} \leqslant 5 \times 10^{-4} ; 0 \leqslant X_{2} \leqslant 10^{-3}\right)$ and in $0.1 M$ $\mathrm{KOH}$ solution. In this way, the composition profile of the hydroxide layer could be modified over a relatively wide range of $\mathrm{Ni}(\mathrm{OH})_{2} / \mathrm{Co}(\mathrm{OH})_{2}$ ratio. The SCE refer- 
ence electrode was connected to the cell through a fritted glass disc and a cup-type glass stopcock lubricated with $0.1 \mathrm{M} \mathrm{KOH}$. Potentials in the text are given in the SHE scale. The counterelectrode was a large-area platinum sheet placed in a separate cell compartment. The precipitated hydroxide electrodes are referred to, below, as thin-or thick-layer electrodes depending on whether $n_{i}(i=0,1,2)<10$ or $n_{i}(i=$ $0,1,2)>20$, respectively.

Runs were made at $25^{\circ} \mathrm{C}$ in $0.1 \mathrm{M} \mathrm{KOH}$ under purified nitrogen gas saturation. Both the precipitating and electrolyte solutions were prepared from analytical-grade (p.a. Merck) reagents and triply distilled water.

The potential/current density $(E / i)$ profiles were recorded by perturbing the electrochemical interface with single (STPS) and repetitive (RTPS) triangular potential sweeps between fixed lower $\left(E_{\mathrm{s}, \mathrm{c}}\right)$ and upper $\left(E_{\mathrm{s}, \mathrm{a}}\right)$ switching potentials at different scan rates $(v)$ in the range $0.001 \mathrm{~V} / \mathrm{s} \leqslant v \leqslant 0.300 \mathrm{~V} / \mathrm{s}$, and with combined triangular potential sweeps and triangular potential sweeps coupled to potential steps as described in previous publications $[12,13,18]$. The nickel to cobalt concentration ratio in the precipitated layer was evaluated by atomic absorption spectrometry (Rank Hilger Atomspek H 1550).

\section{RESULTS}

Voltammetric reponse of $\mathrm{Pt} /$ precipitated $\mathrm{Ni}(\mathrm{OH})_{2}$ and $\mathrm{Pt} /$ precipitated $\mathrm{Co}(\mathrm{OH})_{2}$ electrodes

The voltammetric response of the $\mathrm{Pt} /$ precipitated $\mathrm{Ni}(\mathrm{OH})_{2}$ electrode in the potential range of the $\mathrm{Ni}(\mathrm{II}) / \mathrm{Ni}$ (III) couple (Fig. 1) depends on the quantity of nickel hydroxide precipitated, on the number of repetitive potential cycles and on the characteristics of the potential perturbation program. The corresponding overall reaction in the simplest case is represented by a square-type reaction pathway involving two electron and proton transfer steps coupled to two chemical-type reactions [11]. In the following analysis of the results, current peaks are identified in accordance with the same nomenclature used in previous work [11]. During the charging/discharging cycles, there is a shift of peaks II and III towards more positive potentials and the contribution of peak IV smears out. Simultaneously, during cycling current, peak II becomes wider, its height decreases and, at a constant potential, the transient current associated with the oxygen evolution increases with the duration of the potential cycling (Fig. 1a). Peak IV is much better defined during the first negative potential directed scan, for relatively thick hydrous nickel hydroxide elcctrodes (Fig. 1b). Both the hydrous nickel hydroxide electrooxidation and electroreduction $E / i$ profiles involve a multiplicity of peaks as revealed by the splitting of both the cathodic and the anodic current peaks (Fig. 2) immediately after the electrode was subjected to the potential perturbation programs depicted in the figure. In both cases, the behaviour of precipitated hydrous nickel hydroxide electrodes is similar to that already reported for other, differently prepared, hydrous nickel hydroxide electrodes $[14,17]$. The splitting of the cathodic current peak is 


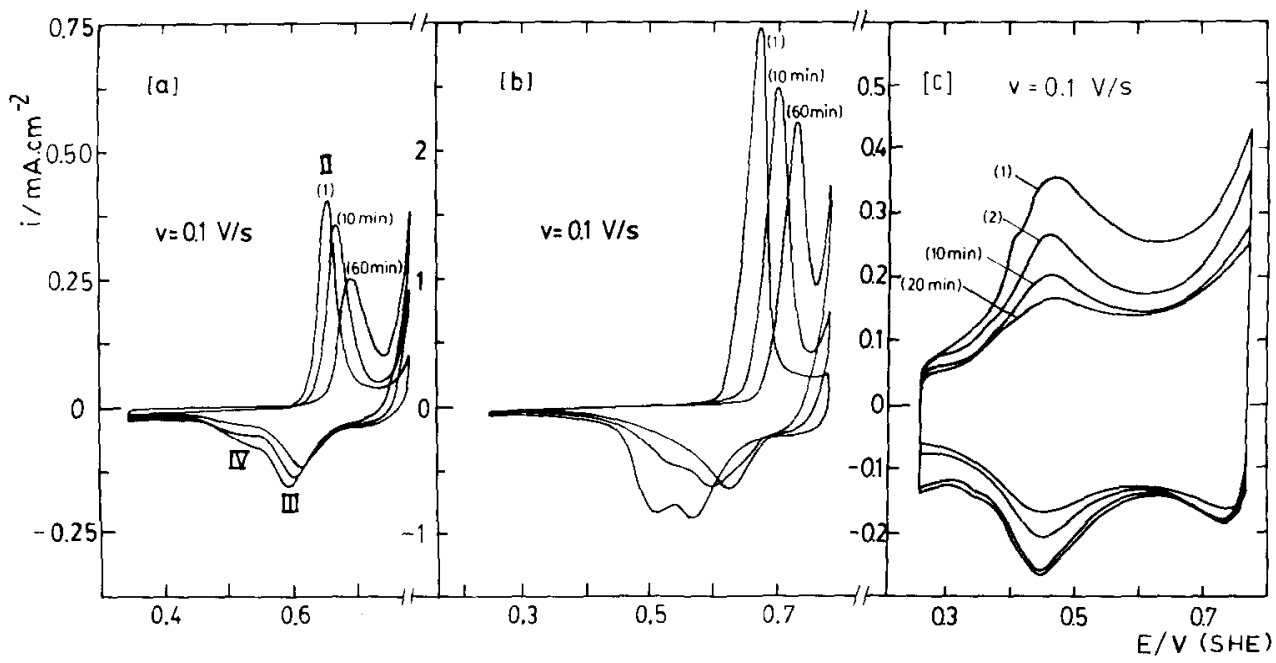

Fig. 1. Potentiodynamic $E / i$ profiles run under BPTR at $0.1 \mathrm{~V} / \mathrm{s}$ for $\mathrm{Pt} / \mathrm{Ni}(\mathrm{OH})_{2} / 0.1 M \mathrm{KOH}$, (a) and (b), and $\mathrm{Pt} / \mathrm{Co}(\mathrm{OH})_{2} / 0.1 M \mathrm{KOH}$ (c). The electrodes were prepared according to procedure $1[X=0$ for (a) and (b), and $X=5 \times 10^{-4}$ and $y=0$ for (c)l. (a) $n_{0}=5$; (b) $n_{0}=50$; (c) $n_{0}=50$. The first profile and those obtained with different durations of the potential cycling are shown. In case (a) current peaks are numbered according to the description already given in previous publications $[11,13,35]$.

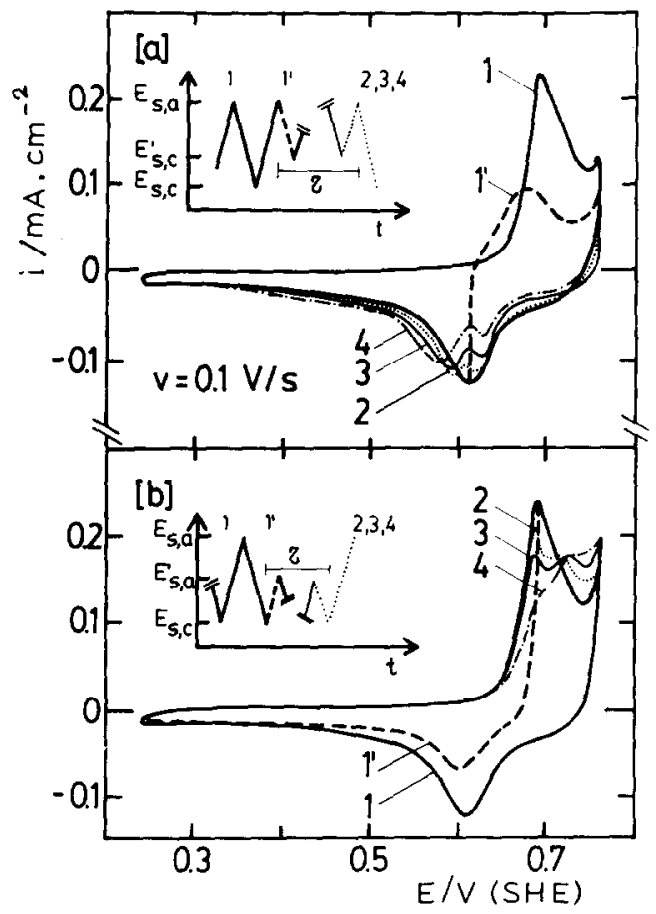

Fig. 2. Potentiodynamic $E / i$ measurements recorded at $0.1 \mathrm{~V} / \mathrm{s}$ for $\mathrm{Pt} / \mathrm{Ni}(\mathrm{OH})_{2} / 0.1 M \mathrm{KOH}$ prepared according to procedure 1 ( $X=0$ and $n_{0}=5$ ). (a) Splitting of the cathodic current peak; (b) Splitting of the anodic current peak. Perturbation programs are shown in the figures. $\tau=1 \mathrm{~min}$ (curve 2); $\tau=5 \mathrm{~min}$ (curve 3); and $\tau=25 \mathrm{~min}$ (curve 4). 
initially in the order of $20 \mathrm{mV}$ and increases up to about $40 \mathrm{mV}$ as $\tau$, the duration of the intermediate RTPS, increases, while that of the anodic current peak is about 40 $\mathrm{mV}$.

The voltammetric response of the $\mathrm{Pt} /$ precipitated $\mathrm{Co}(\mathrm{OH})_{2}$ electrode (Fig. 1c) in the 0.26 to $0.77 \mathrm{~V}$ range exhibits complex anodic and cathodic current peaks which have already been described for the hydrous cobaltous hydroxide electrodes formed by the electrodissolution of cobalt in base [16]. The main current peaks appear at potentials lower than those of the $\mathrm{Ni}$ (II)/ $\mathrm{Ni}$ (III) redox couple, but the overall charge during the charging/discharging processes decreases during the potential cycling.

\section{Electrochemical response of coprecipitated $\left(\mathrm{Ni}(\mathrm{OH})_{2}+\mathrm{Co}(\mathrm{OH})_{2}\right)$ electrodes}

The voltammogram of the $\mathrm{Pt} /$ co-precipitated $\left[\mathrm{Ni}(\mathrm{OH})_{2}+\mathrm{Co}(\mathrm{OH})_{2}\right]$ electrode (Fig. 3) run in conditions comparable with those corresponding to Fig. 1 shows, in principle, for a relatively thin hydroxide layer, the main current peaks associated with the $\mathrm{Ni}(\mathrm{II}) / \mathrm{Ni}(\mathrm{III})$ couple but, after prolonged potential cycling, the reactions commence at potentials lower than those occurring in the absence of $\mathrm{Co}(\mathrm{OH})_{2}$. Furthermore, in the co-precipitated electrode there is no change of the peak potentials on cycling during the charging/discharging process, but there is an

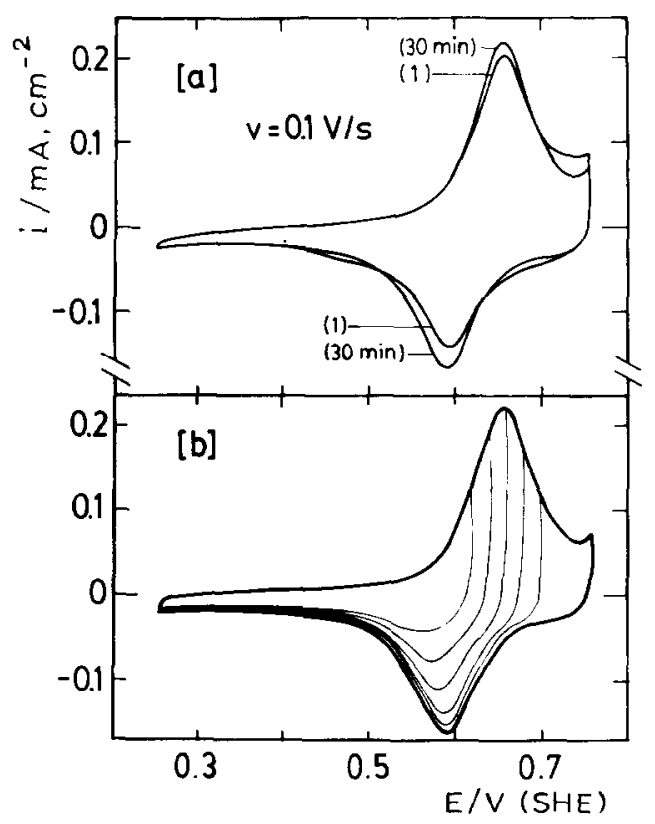

Fig. 3. Potentiodynamic response at $0.1 \mathrm{~V} / \mathrm{s}$ of co-precipitated hydrous $\left[\mathrm{Ni}(\mathrm{OH})_{2}+\mathrm{Co}(\mathrm{OH})_{2}\right]$ electrode prepared according to procedure $1\left(X=10^{-4}, n_{0}=5\right)$. (a) $E / i$ profiles under RTPS. The first profile and the stabilized profile obtained after a 30-min potential cycling are shown; (b) Influence of $E_{\mathrm{s}, \mathrm{a}}$ on the $E / i$ profile. 
apparent slight increase in the charge related to the active electrode material. When $E_{\text {s.a }}$ is gradually increased, the voltammogram shows that the $\mathrm{Ni}$ (II)/Ni(III) redox reaction behaves as a fast reaction from the very early stages, (Fig. 3b), i.e. the stabilized RTPS $E / i$ profile is attained in a time much shorter than in the absence of $\mathrm{Co}(\mathrm{OH})_{2}$ (compare Figs. $1 \mathrm{a}$ and 3a).

Once the stabilized $E / i$ profile has been attained, the anodic $\left(Q_{\mathrm{a}}\right)$ to cathodic $\left(Q_{\mathrm{c}}\right)$ charge ratio is always equal to one, both for precipitated $\mathrm{Ni}(\mathrm{OH})_{2}$ electrodes and co-precipitated $\left[\mathrm{Ni}(\mathrm{OH})_{2}+\mathrm{Co}(\mathrm{OH})_{2}\right]$ electrodes, but this is not the case for the first triangular potential sweep, where the $Q_{\mathrm{a}} / Q_{\mathrm{c}}$ ratio is always slightly greater than one. This effect is enhanced on increasing the $\mathrm{Co}^{2+}$ ion content in the hydroxide layer.

Co-precipitated electrodes exhibit the same type of peak multiplicity (Fig. 4) caused by the potentiodynamic ageing perturbation program as that encountered for

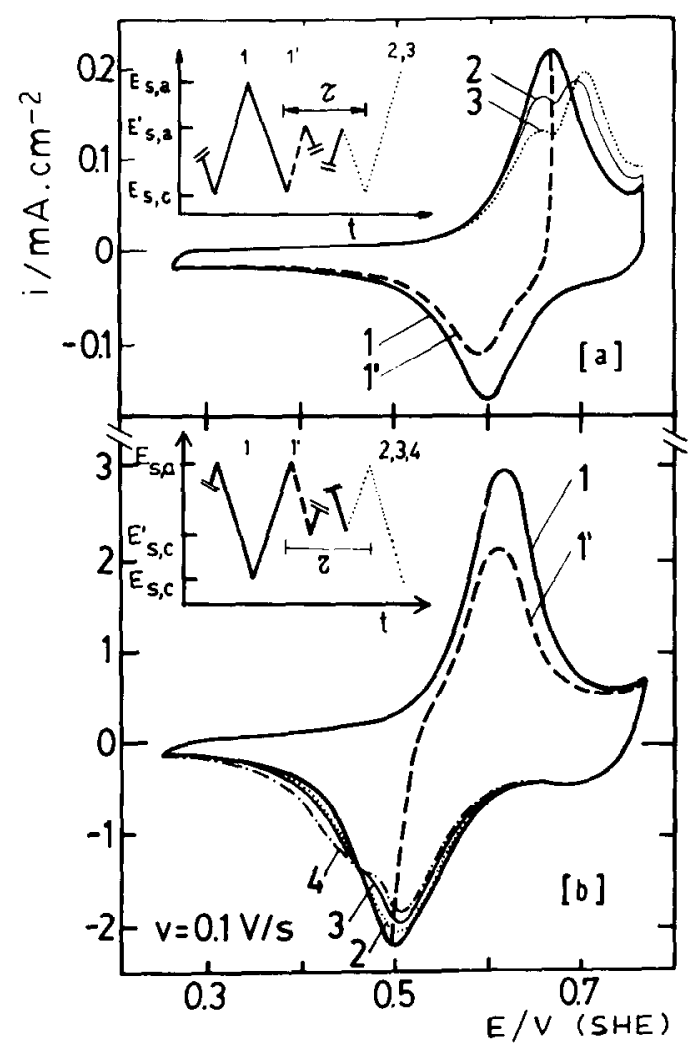

Fig. 4. Splitting of the anodic (a) and cathodic (b) current peaks for Pt/co-precipitated hydrous $\left[\mathrm{Co}(\mathrm{OH})_{2}+\mathrm{Ni}(\mathrm{OH})_{2}\right]$ electrodes prepared according to procedure 1. (a) $X=10^{-4}, y=5 \times 10^{-4}, n_{0}=5$; $\tau=7 \mathrm{~min}$ (curve 2); $\tau=20 \mathrm{~min}$ (curve 3); (b) $X=5 \times 10^{-4}, y=5 \times 10^{-4}, n_{0}=50, \tau=1$ min (curve 2), $\tau=5 \min$ (curve 3), $\tau=25 \min$ (curve 4). 
plain hydrous nickel hydroxide electrodes $[11,14]$. The peak potentials, however, are shifted towards more negative values compared to those obtained with precipitated $\mathrm{Ni}(\mathrm{OH})_{2}$ electrodes, and the splitting of cathodic peak III is considerably hindered when $\mathrm{Co}(\mathrm{OH})_{2}$ is present in the hydroxide layer. In this case, the activation of the $\mathrm{Ni}(\mathrm{II})$ to $\mathrm{Ni}$ (III) electrooxidation observed during the intermediate RTPS is practically cancelled out (Fig. 4b). Moreover, the anodic peak splitting also changes considerably according to the hydroxide layer composition, particularly in the anodic current produced at $E_{\mathrm{s}, \mathrm{a}}$ which becomes much greater for precipitated $\mathrm{Ni}(\mathrm{OH})_{2}$ electrodes than for co-precipitated electrodes after application of the potentiodynamic ageing program (Fig. $4 \mathrm{a}$ ).

The stabilized pseudo-capacitance/potential plots for co-precipitated electrodes depend considerably on the amount of active material and on the potential sweep rate (Fig. 5). Thus, for relatively thick layers, as $v$ decreases the multiplicity of both the anodic and cathodic peaks becomes more pronounced and the overall voltammetric response corresponds to a decreasing polarization of the electrochemical reactions (Fig. 5a). On the other hand, for relatively thin co-precipitated electrodes, the peak multiplicity is no longer clear. In this case, as $v$ decreases the anodic current increase observed at ca. $0.7 \mathrm{~V}$ is accompanied by a cathodic current increase in the 0.5 to $0.3 \mathrm{~V}$ range (Fig. $5 \mathrm{~b}$ ).

The voltammetric response of co-precipitated electrodes depends on the $\mathrm{Co}^{2+} / \mathrm{Ni}^{2+}$ concentration ratio in the precipitating solutions (Fig. 6a). It should be mentioned that the $\mathrm{Co}^{2+} / \mathrm{Ni}^{2+}$ concentration ratio in solution is also maintained in

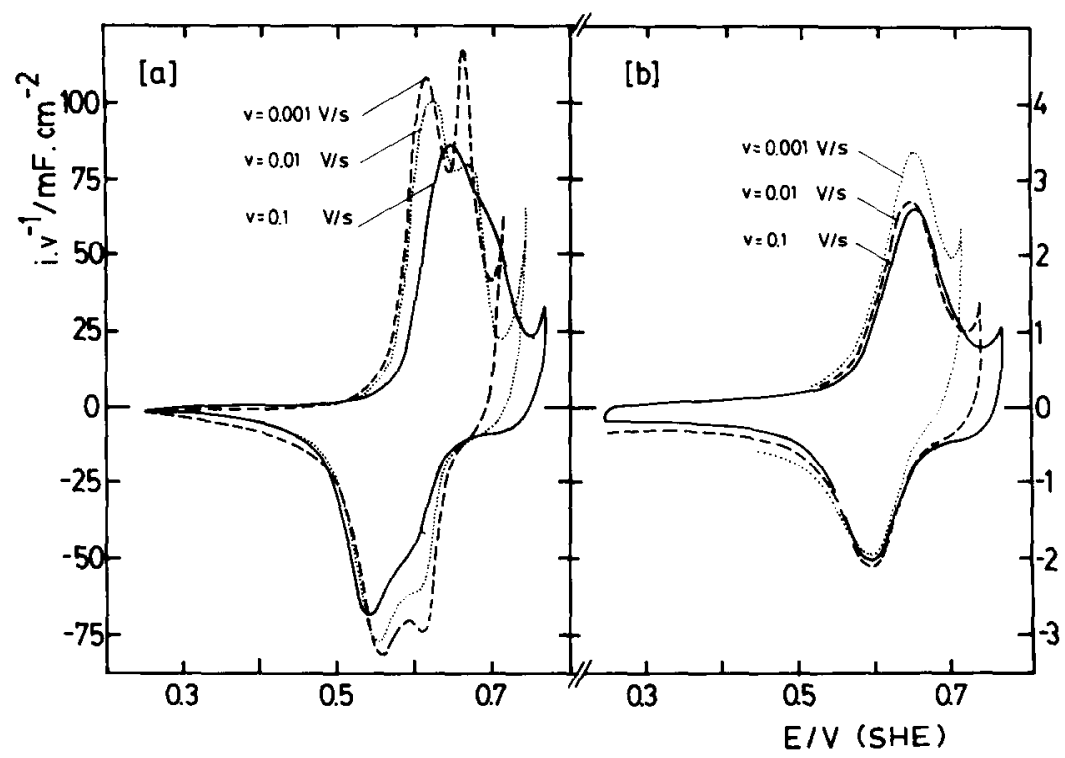

Fig. 5. Influence of $v$ on the stabilized RTPS $E / i$ curves. Co-precipitated hydrou $\left[\mathrm{Ni}(\mathrm{OH})_{2}+\mathrm{Co}(\mathrm{OH})_{2}\right]$ electrodes prepared according to procedure 1. $X=10^{-4} ; y=5 \times 10^{-4}$. (a) $n_{0}=130$; (b) $n_{0}=5$. 
the co-precipitated hydroxide layer. The correlation between $n_{0}$ and the actual amount of precipitated hydrous nickel hydroxide was established by dissolving the latter in $1 \mathrm{ml}$ nitric acid solution ( $50 \%$ by volume) and evaluating the concentration (c) of the soluble cation by atomic absorption spectrophotometry. In the $0<n_{0}<80$ range, a linear correlation is obtained between $c$ and $n_{0}$. For precipitated $\mathrm{Ni}(\mathrm{OH})_{2}$ electrodes, providing that the growth rate of the $\mathrm{Ni}(\mathrm{OH})_{2}$ layer is uniform, the

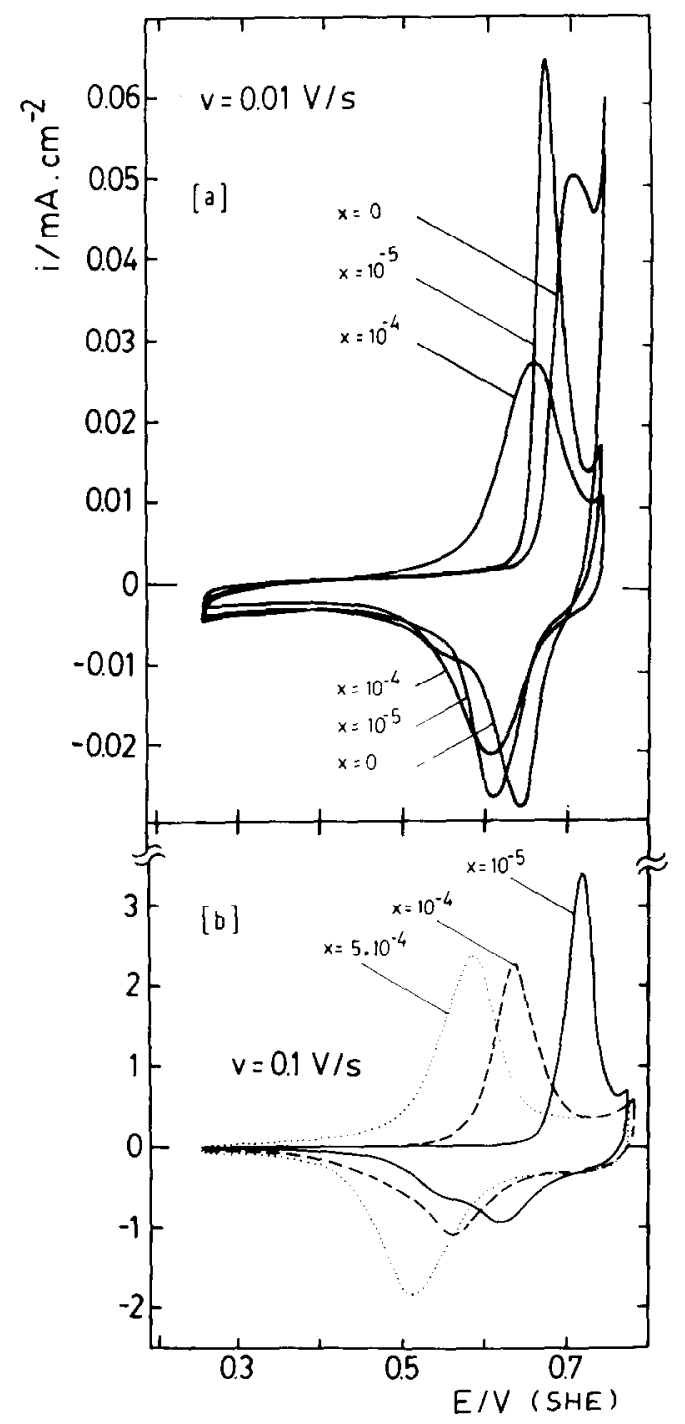

Fig. 6. Influence of $x$ on the stabilized RTPS $E / i$ profiles employing electrodes prepared according to procedure 1. $Y=5 \times 10^{-4}$; (a) $n_{0}=5, v=0.01 \mathrm{~V} / \mathrm{s}$; (b) $n_{0}=50, v=0.1 \mathrm{~V} / \mathrm{s}$. 
average hydroxide layer thickness is proportional to $n_{0}$. Results show that, in the concentration range covered by the present work, the $\mathrm{Co}^{2+} \mathrm{Ni}^{2+}$ concentration ratio in solution is maintained in the co-precipitated hydroxide. For relatively thin layers, both the anodic and the cathodic current peaks move in the negative potential direction and become wider as the $\mathrm{Co}^{2+} / \mathrm{Ni}^{2+}$ concentration ratio approaches one. This relationship is more evident when relatively thick layers and large values of $v$ are considered (Fig. $6 \mathrm{~b}$ ). Both the anodic and the cathodic peak potentials decrease proportionally to $\log \left(c_{\mathrm{Co}^{2+}}\right)$ in the precipitating solution.

\section{Electrochemical response of electrodes made of alternate hydroxide layers}

In the case of electrodes made of alternate $\mathrm{Ni}(\mathrm{OH})_{2}$ and $\mathrm{Co}(\mathrm{OH})_{2}$ layers, the $E / i$ profiles depend largely on the precipitation sequence of the hydroxide layers. In a first series of experiments where the $\mathrm{Ni}^{2+} / \mathrm{Co}^{2+}$ concentration ratio is 5 and the electrode structure can be schematically represented as $\mathrm{Pt} / \mathrm{Ni}(\mathrm{OH})_{2}$ thick layer $/\left[\mathrm{Co}(\mathrm{OH})_{2}+\mathrm{Ni}(\mathrm{OH})_{2}\right]$ thin layer (Fig. 7a), the pseudo-capacitance/potential profile resembles that of a precipitated $\mathrm{Ni}(\mathrm{OH})_{2}$ electrode, but under comparable

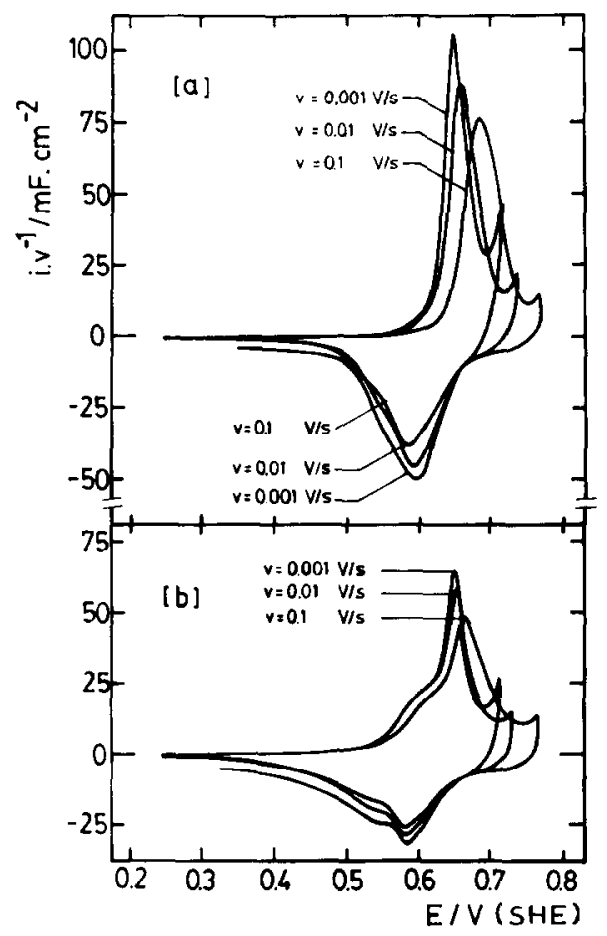

Fig. 7. RTPS pseudo-capacitance/potential profiles obtained at different $v$ with sandwich-like electrodes prepared accoiding to procedure 2. (a) $n_{1}=40, X_{1}=0 ; n_{2}=10, X_{2}=10^{-4} ; Y_{1}=Y_{2}=5 \times 10^{-4}$. (b) $n_{1}=40, X_{1}=10^{-4} ; n_{2}=10, X_{2}=0 ; Y_{1}=Y_{2}=5 \times 10^{-4}$. 
conditions the peak potentials corresponding to the $\mathrm{Ni(II)/Ni(III)} \mathrm{conjugated}$ couple in the former case become slightly more negative than in the latter. This shift is more pronounced and the transient anodic current at $E_{\mathrm{s}, \mathrm{a}}$ is appreciably enhanced when $v$ decreases. Moreover, the voltametric response of an electrode approaching the $\mathrm{Pt} /\left[\mathrm{Co}(\mathrm{OH})_{2}+\mathrm{Ni}(\mathrm{OH})_{2}\right]$ thick layer $/ \mathrm{Ni}(\mathrm{OH})_{2}$ thin layer structure (Fig. $7 \mathrm{~b}$ ), involves an overall charge smaller than that shown in Fig. 7a under comparable precipitation conditions. Correspondingly, there is a smaller shift in the peak potentials and a greater depolarization for the anodic reaction proceeding at $E_{\mathrm{s} \text { a }}$. For an electrode of structure $\mathrm{Pt} / \mathrm{Co}(\mathrm{OH})_{2}$ thick layer $/\left(\mathrm{Ni}(\mathrm{OH})_{2}+\mathrm{Co}(\mathrm{OH})_{2}\right)$ thin layer the stabilized pseudo-capacitance/potential profile changes from one exhibiting an anodic double peak to one involving an anodic current peak with a hump at the positive potential side and a wide cathodic current peak (Fig. 8a). This change occurs in a relatively short period of potential cycling at $v=0.1 \mathrm{~V} / \mathrm{s}$ between $E_{\mathrm{s}, \mathrm{c}}=0.25 \mathrm{~V}$ and $E_{\mathrm{s}, \mathrm{a}}=0.77 \mathrm{~V}$. In this case the pseudo-capacitance/potential profile remains nearly independent of $v$ (Fig. 8b) except for the depolarization effect occurring at $E_{\mathrm{s}, \mathrm{a}}$, although the latter is less pronounced than that shown in Fig. $7 \mathrm{~b}$.

From these results one concludes that the greatest depolarization of the overall electrochemical reaction occurs when the inner layer involves a co-precipitation of

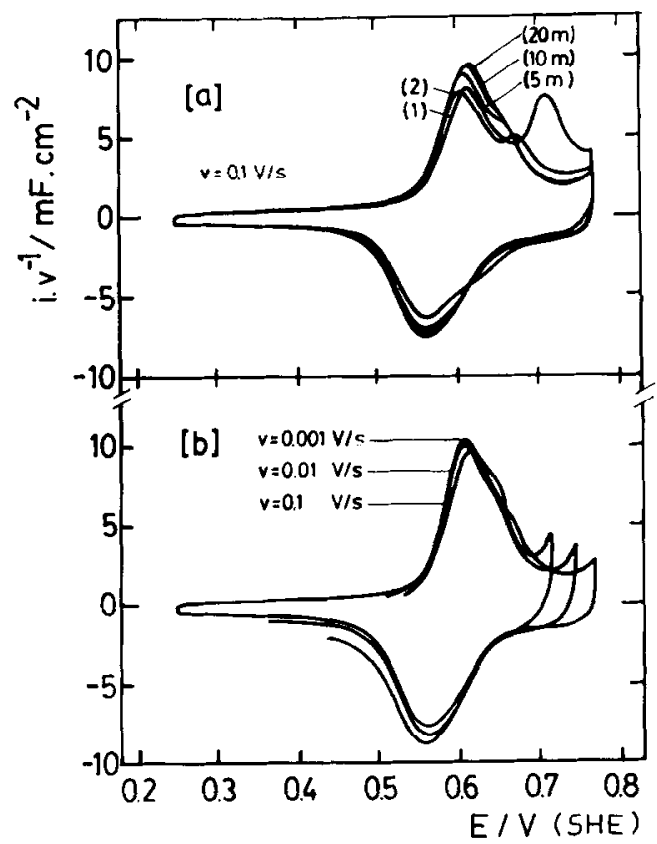

Fig. 8. RTPS pseudo-capacitance/potential profiles with sandwich-like electrodes prepared according to procedure 2. $n_{1}=40, X_{1}=10^{-4}, Y_{1}=0$; and $n_{2}=10, X_{2}=10^{-4}, Y_{2}=5 \times 10^{-4}$. (a) First and second profiles and those resulting after 5-, 10- and 20-min potential cycling at $0.1 \mathrm{~V} / \mathrm{s}$ are shown. (b) Influence of $v$ on the stabilized curves. 
both hydrous cobalt and nickel hydroxides (Fig. 9). Furthermore, for $n_{1}=40$ and $n_{2}=10$, the structure of the layer approaches a sandwich-like structure consisting of a hydrous cobalt hydroxide outer layer on a hydrous nickel hydroxide inner layer in contact with the platinum surface, and its electrochemical response is close to that of the precipitated $\mathrm{Ni}(\mathrm{OH})_{2}$ electrode. When the outer layer corresponds to a mixture of both hydrous cobalt hydroxide and nickel hydroxide, its electrochemical response tends to that of the co-precipitated hydroxide electrode. When the inner layer is made of hydrous cobalt hydroxide, a current probably associated with the $\mathrm{Co} / \mathrm{Co}(\mathrm{OH})_{2}$ redox couple is recorded below $0.6 \mathrm{~V}$. The different currents associated with the hydrous cobalt hydroxide and the hydrous nickel hydroxide electrodes depend on the ratio of each active material. The corresponding current contributions, however, tend to overlap in a potential range which is intermediate between the potential ranges of the single metal hydroxide electrode reactions (Fig. 9, curve 4). The dependence of the voltammograms on $v$ changes according to the precipitation procedure used to form the metal hydroxide layer (Figs. 7 and 8).

In a second series of experiments the $\mathrm{Ni}^{2+} / \mathrm{Co}^{2+}$ concentration ratio was kept equal to 0.5 in order to increase the influence of $\mathrm{Co}(\mathrm{OH})_{2}$ in the overall electrochemical response. Thus, when a $\mathrm{Pt} /$ precipitated $\mathrm{Co}(\mathrm{OH})_{2}$ (either thin or thick layer) electrode is gradually covered with a hydrous nickel hydroxide layer of increasing thickness, the voltammogram approaches that of the precipitated $\mathrm{Ni}(\mathrm{OH})_{2}$ electrode (Fig. 10), although, in the former case, the potentials of current peaks II and III

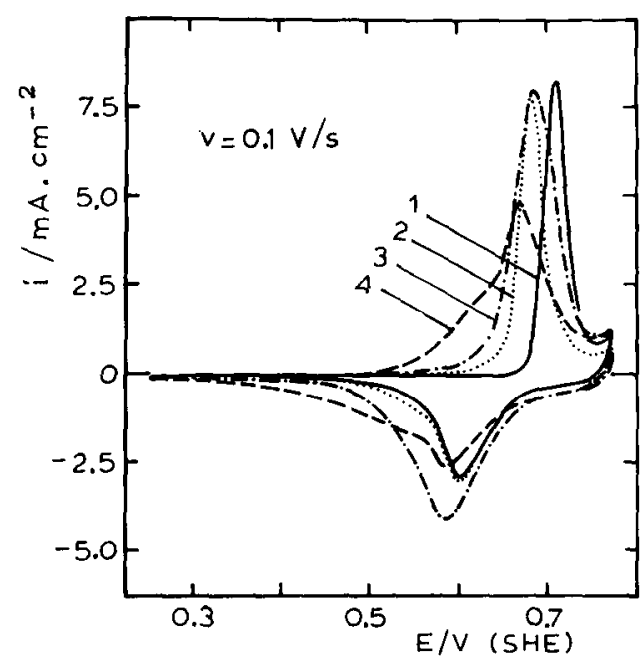

Fig. 9. Stabilized RTPS $E / i$ profiles obtained at $v=0.1 \mathrm{~V} / \mathrm{s}$ with sandwich-like electrodes prepared according to procedure 2 by changing the precipitation sequence. Curve $1(-): n_{1}=40, X_{1}=0$, $Y_{1}=5 \times 10^{-4}$; and $n_{2}=10, X_{2}=10^{-4}, Y_{2}=0$. Curve $2(\cdots \cdots)$ : the preparation sequence consisted of (i) $X=0, Y=5 \times 10^{-4}$, (ii) $0.1 \mathrm{MKOH}$, (iii) $X=10^{-4}, Y=0$, and (iv) $0.1 \mathrm{M} \mathrm{KOH}$, with $n_{0}=50$. Curve $3(-\cdot-): n_{1}=40, X_{1}-0, Y_{1}=5 \times 10^{-4}$; and $n_{2}=10, X_{2}=10^{-4}, Y_{2}=5 \times 10^{-4}$. Curve $4(------)$; $n_{1}=40, X_{1}=10^{-4}, Y_{1}=5 \times 10^{-4}$; and $n_{2}=10, X_{2}=0, Y_{2}=5 \times 10^{-4}$. 


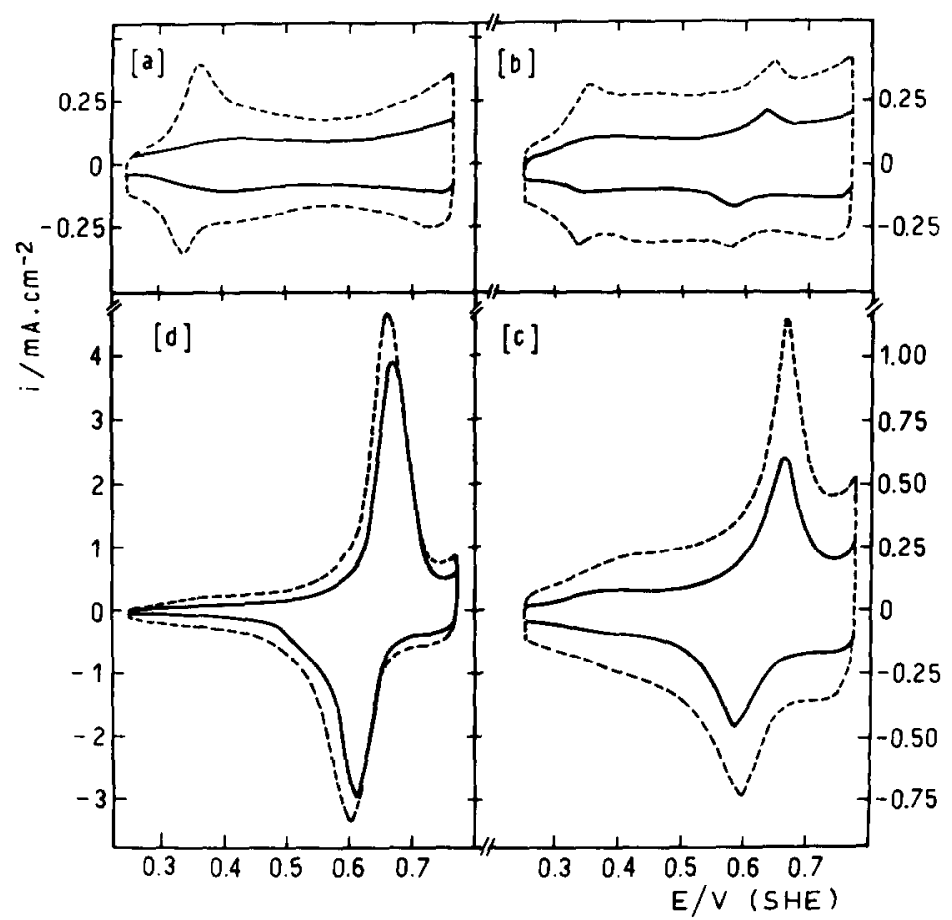

Fig. 10. Stabilized RTPS potentiodynamic $E / i$ profiles at $0.1 \mathrm{~V} / \mathrm{s}$, with electrodes prepared according to procedure 2. Influence of hydrous $\mathrm{Ni}(\mathrm{OH})_{2}$ prepared on a previously precipitated $\mathrm{Co}(\mathrm{OH})_{2}$ layer. $X_{1}=10^{-3}, Y_{1}=0 ; X_{2}=0, Y_{2}=5 \times 10^{-4}$. (a) (—) $n_{0}=20 ;(--\cdots-) n_{0}=80$ [blanks in the

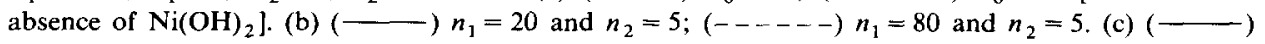
$n_{1}=20$ and $n_{2}=20 ;(-\cdots+-) n_{1}=80$ and $n_{2}=20$. (d) (- $n_{1}=20$ and $n_{3}=80 ;(--\cdots)$ $n_{1}=80$ and $n_{2}=80$.

become more negative and the corresponding peak potential difference smaller than those recorded for the latter.

When the electrode structure is inverted so that the inner layer is made of hydrous nickel hydroxide and the outer layer corresponds to hydrous cobalt hydroxide (Fig. 11 ), the $E / i$ profile is apparently determined by the $\mathrm{Ni}(\mathrm{II}) / \mathrm{Ni}(\mathrm{III})$ redox couple, although the degree of reversibility increases when the inner layer is made of hydrous cobalt hydroxide. In this case, the greatest depolarization effect in the charging/discharging process and the smallest peak potential difference is observed (Fig. 11).

\section{Potential decay under open circuit}

The potential transients under open circuit from either $E_{\mathrm{s}, \mathrm{c}}$ or $E_{\mathrm{s}, \mathrm{a}}$ resulting from a stabilized voltammogram also depend on the hydroxide layer structure and on the amount of each reacting species. The greatest difference in the potential decay curves 


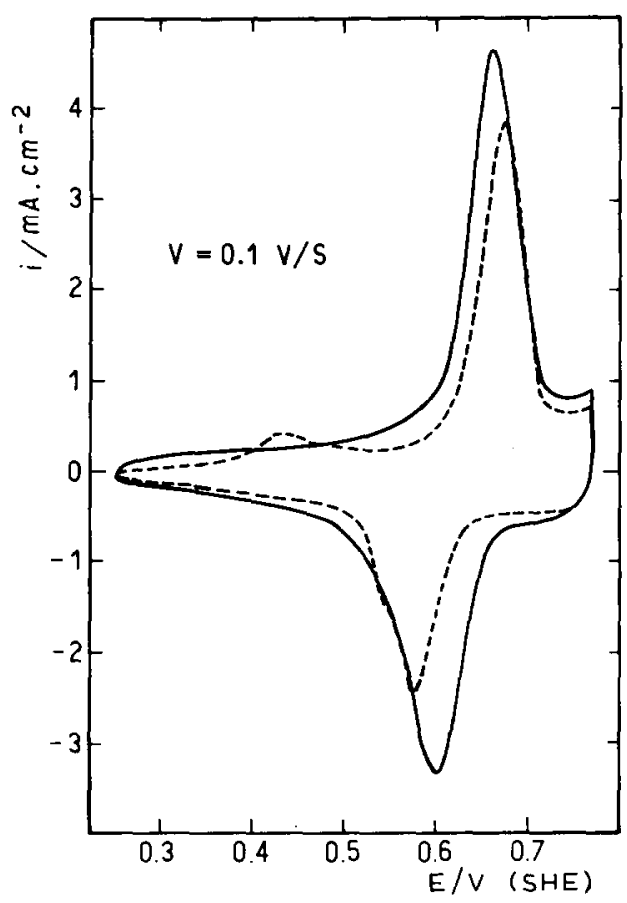

Fig. 11. Stabilized $E / i$ potentiodynamic profiles at $0.1 \mathrm{~V} / \mathrm{s}$ with electrodes prepared according to procedure 2. (-$n_{1}=80, X_{1}=10^{-3}, Y_{1}=0$; and $n_{2}=80, X_{2}=0, Y_{2}=5 \times 10^{-4}$.

appears when the current is switched off at $E_{\mathrm{s}, \mathrm{c}}$ (Fig. 12). When the open circuit potential is measured from $E_{\mathrm{s}, \mathrm{a}}$, in any case the rest potential of the $\mathrm{Ni(II)/Ni(III)}$ redox couple (Fig. 12a) is approached. But in those runs started from $E_{\mathrm{s}, \mathrm{c}}$, when either the first layer corresponds to $\mathrm{Co}(\mathrm{OH})_{2}$ or the thickness of the outer $\mathrm{Co}(\mathrm{OH})_{2}$ layer has been gradually increased (Fig. 12b), the open circuit potential becomes closer to that of the precipitated $\mathrm{Co}(\mathrm{OH})_{2}$ layer electrode. Nevertheless, the limiting open circuit potentials resulting either from $E_{\mathrm{s}, \mathrm{a}}$ or $E_{\mathrm{s}, \mathrm{c}}$ are close to the potentials of the corresponding current peaks in the voltammograms where the potential changes in the positive or negative direction, respectively.

Influence of hydrous nickel hydroxide and hydrous cobalt hydroxide on the voltammetric response of platinum

The presence of the hydroxide layer also changes the characteristics of polycrystalline platinum in base electrolyte in the potential range where hydrogen and oxygen adatom electrosorption processes take place [14] (Fig. 13). In general, a layer of either hydrous cobalt hydroxide or hydrous nickel hydroxide in contact with platinum decreases the hydrogen adatom electrodesorption charge, but the overall 


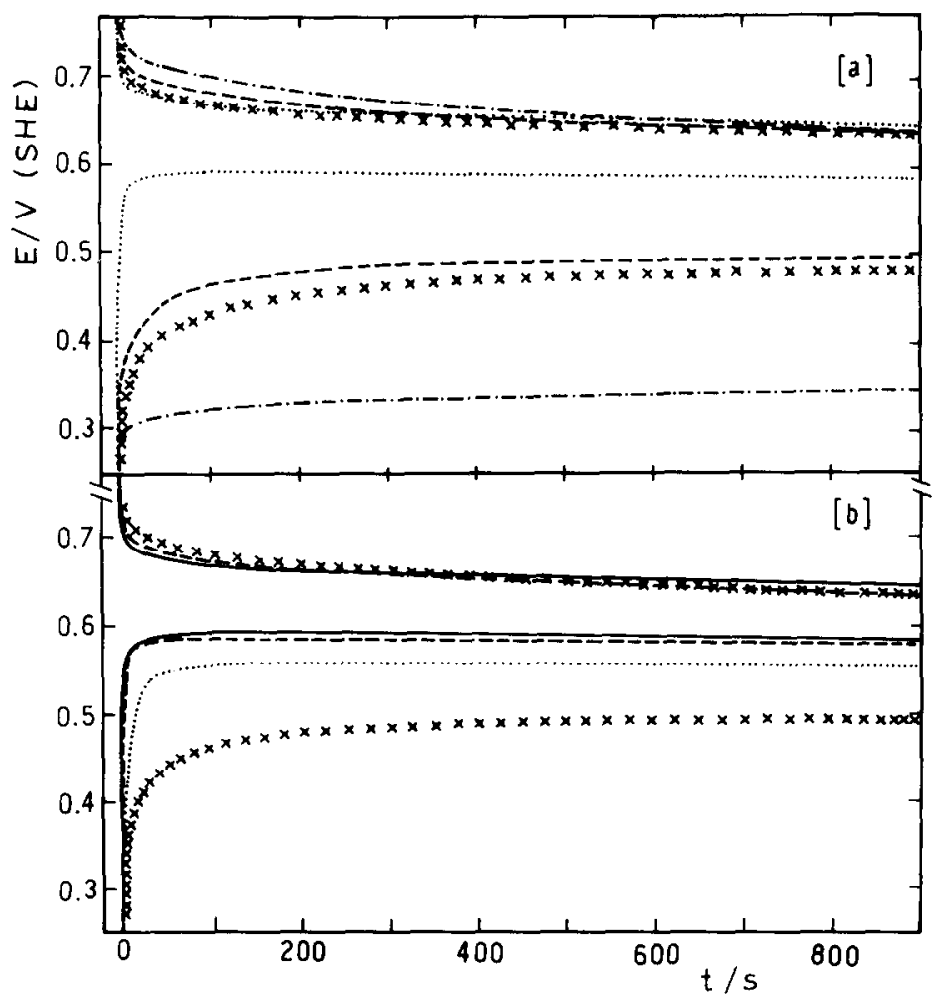

Fig. 12. Potential transients under open circuit conditions resulting from $E_{\mathrm{s}, \mathrm{a}}$ and $E_{\mathrm{s}, \mathrm{c}}$ after obtaining the stabilized RTPS $E / i$ profiles. (a) $(\cdots \cdots)$ blank with precipitated hydrous $\mathrm{Ni}(\mathrm{OH})_{2}, n_{0}=80, Y=5 \times$ $10^{-4}, X=0 ;(\cdot-\cdot-\cdot)$ blank with precipitated hydrous $\mathrm{Co}(\mathrm{OH})_{2}, n_{0}=80, x=10^{-3}, Y=0 ;(-----)$ and $(\times)$ correspond to electrode prepared as indicated in Fig. 11 for $\left(---_{-}\right)$and (respectively. (b) Influence of the hydrous $\mathrm{Co}(\mathrm{OH})_{2}$ layer $\left(X=10^{-3}\right)$ prepared on a thick hydrous $\mathrm{Ni}(\mathrm{OH})_{2}$ layer $\left(n_{0}=80, Y=5 \times 10^{-4}\right)$ previously precipitated on platinum. (- $) n_{2}=0$ (blank); $(\cdots \cdots) n_{2}=5 ;(\cdots) n_{2}=20 ;(\times) n_{2}=80$.

influence of the hydroxide layer on the voltammogram of platinum in base also depends on the hydroxide layer structure. Thus, the potential cycling of a $\mathrm{Pt} / \mathrm{Co}(\mathrm{OH})_{2} / \mathrm{Ni}(\mathrm{OH})_{2}$ electrode in base covering the -0.72 to $0.76 \mathrm{~V}$ potential range produces a yellow-tinged platinum surface. In this case, to recover the characteristic voltammogram of platinum in base the electrode must be treated for $15 \mathrm{~min}$ with a hot $1: 1 \mathrm{HNO}_{3}+\mathrm{H}_{2} \mathrm{SO}_{4}$ mixture. This indicates that a relatively in soluble species is formed during the electrochemical measurements. This effect is absent when the structure of the electrode involves a hydrous nickel hydroxide the inner layer. 


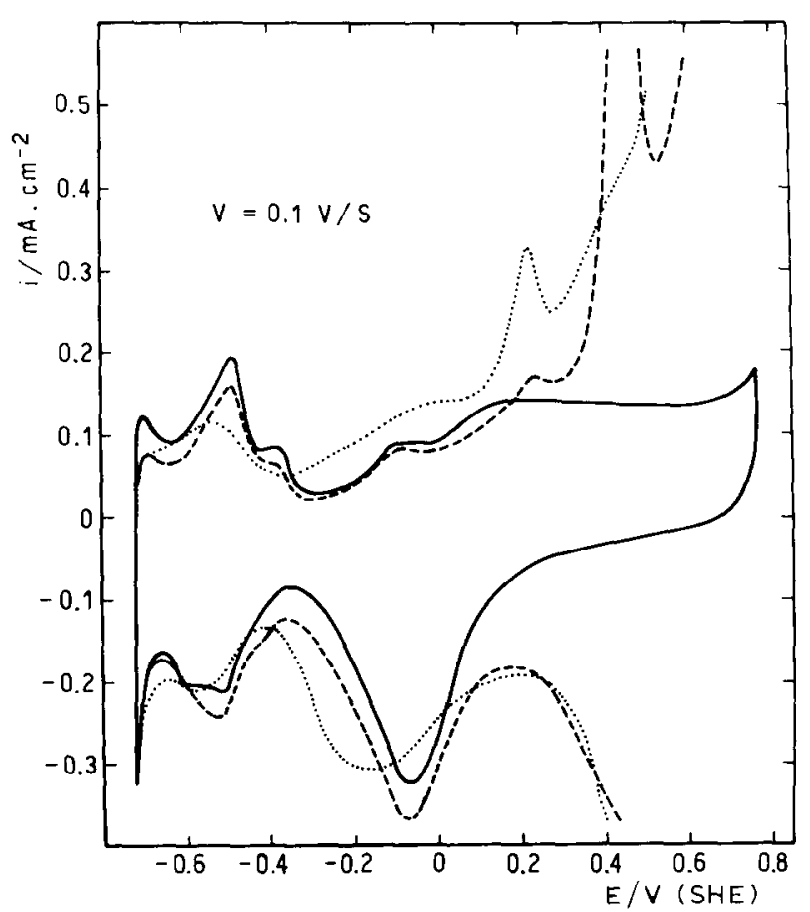

Fig. 13. Influence of hydrous $\mathrm{Ni}(\mathrm{OH})_{2}$ and $\mathrm{Co}(\mathrm{OH})_{2}$ layers on the potentiodynamic response of platinum in $0.1 \mathrm{M} \mathrm{KOH}$ in the potential ranges of $\mathrm{H}$ - and O-electrosorption. ( - ) $\mathrm{Pt} / 0.1 \mathrm{M} \mathrm{KOH}$ (blank); $(-----)$ and $(\cdots \cdots)$ refer to the stabilized profiles shown in Fig. 11 as $\left(----_{-}\right)$and $(--$, respectively.

\section{DISCUSSION}

The non-stationary electrochemical behaviour of the electrodes containing hydrous nickel and cobalt hydroxides in the alkaline electrolyte depends on the preparation procedure of the complex $\mathrm{Pt} /$ metal hydroxide layer electrode. In principle, three distinguishable situations can be discussed which can be associated with the following schemes of the electrode/solution interface: (i) $\mathrm{Pt} / \mathrm{hydrous}$ (nickcl + cobalt) hydroxide/electrolyte; (ii) $\mathrm{Pt} /$ hydrous nickel hydroxide/hydrous cobalt hydroxide/electrolyte and (iii) $\mathrm{Pt} /$ hydrous cobalt hydroxide/hydrous nickel hydroxide/electrolyte. In case (i) the co-precipitated layer of metal hydroxides quite likely involves a homogeneous distribution of the constituents, while cases (ii) and (iii) represent the structures which are approached by the different preparation procedures. For cases (ii) and (iii) the experimental results are consistent with the fact that the initial hydroxide layer structure is maintained in the relatively short time range of the electrochemical run, but there is no definite proof that this actually occurs in the long time range.

The voltammetric response of co-precipitated hydroxide electrodes in base differs 
considerably from the responses of either precipitated hydrous nickel hydroxide or precipitated hydrous cobalt hydroxide electrodes. Thus, the greatest electrochemical reactivity corresponding to the conjugated redox processes in the co-precipitated electrodes occurs in a potential range inbetween those corresponding to precipitated $\mathrm{Ni}(\mathrm{OH})_{2}$ and precipitated $\mathrm{Co}(\mathrm{OH})_{2}$ electrodes. There is a net decrease of the conjugated peak potentials associated with the $\mathrm{Ni}(\mathrm{II}) / \mathrm{Ni}$ (III) redox couple, which is directly proportional to $\log \left(c_{\mathrm{Co}^{2+}}\right)$ in the precipitating solution. Moreover, in the co-precipitated electrodes, the stabilized voltammogram is obtained after only a few potential scans and the splitting of both the anodic and cathodic current peaks found in hydrous nickel hydroxide electrodes is effectively hindered. The increase in rate of these reactions becomes more evident when the $\mathrm{Co}^{2+} / \mathrm{Ni}^{2+}$ ion concentration ratio in the precipitating solution increases and when relatively thick-layer electrodes are involved.

The influence of the average thickness of the hydrous nickel hydroxide layer on the changes produced during cycling in the electrochemical behaviour of hydrous nickel hydroxide electrodes is evident when the anodic currents in the potential neighbourhood of $E_{s, \mathrm{a}}$ are compared (Fig. 1). In the potential range $0.75-0.78 \mathrm{~V}$ there is a current contribution due to the OER from the discharge of hydroxyl ions, which might, in principle, be proportional to the amount of active material, i.e. to the corresponding $n_{0}$ values. However, the current ratio for $n_{0}=50$ and $n_{0}=5$, resulting from Fig. 1 once the stabilized $E / i$ profile has been attained, is only about 5 , instead of 10. This result indicates that thin hydrous nickel hydroxide layers are apparently more efficient than thick layers in producing an increase in the anodic current at $E_{\mathrm{s}, \mathrm{a}}$. On the other hand, the first voltammetric cycle shows that the anodic current ratio approaches 10 at potentials lower then $E_{\mathrm{s}, \mathrm{a}}$ and decreases to about 5 as the potential becomes more positive. This fact is in good agreement with recently discussed data on the increase of the $Q_{\mathrm{a}} / Q_{\mathrm{c}}$ ratio above one during the first potential scan $[43,44]$, and indicates that in the $0.75 \mathrm{~V}$ range there are at least two anodic current contributions, one corresponding to the initial electrooxidation of the metal hydroxide layer and another related to the oxygen reaction. The former disappears as the potential becomes more positive and after prolonged potential cycling. On the other hand, the presence of co-precipitated hydrous cobalt hydroxide produces an anodic current increase in the $0.76-0.80 \mathrm{~V}$ range which is directly proportional to the ratio of the amounts of corresponding active materials. This result is consistent with a hindrance to the ageing of the hydrous nickel hydroxide layer produced by the presence of hydrous cobalt hydroxide.

The behaviour of co-precipitated hydroxide electrodes can be interpreted in terms of a loose nickel hydroxide layer structure promoted by the presence of hydrous cobalt hydroxide. This open structure which remains more or less unchanged for a relatively long time during the potential cycling is able to incorporate hydroxyl ions from solution [44]. This causes the disappearance of ageing effects in the voltammograms (Fig. 4).

The voltammograms of co-precipitated electrodes indicate that the $\mathrm{Co}$ (II) $/ \mathrm{Co}$ (III) and $\mathrm{Ni}(\mathrm{II}) / \mathrm{Ni}(\mathrm{III})$ redox reactions are largely coupled and the linking species can be 
taken to be the hydroxyl ion inserted into the hydroxide lattice. Thus, the overall initial reaction occurring in the co-precipitated hydroxide electrode is:

$\mathrm{Co}^{2+}($ film $)=\mathrm{Co}^{3+}($ film $)+e^{-}$

The threshold potential of reaction (1) moves in the positive direction as the proportion of hydrous cobalt hydroxide in the co-precipitated layer decreases. When this reaction occurs in the presence of inserted hydroxyl ion, the latter can be oxidized according to:

$\mathrm{Co}^{3+}($ film $)+\left(\mathrm{OH}^{-}\right)_{i} \rightleftarrows \mathrm{Co}^{2+}($ film $)+(\mathrm{OH})_{i}$

where $(\mathrm{OH})_{i}$ denotes either a discharge $\mathrm{OH}$ or an active oxygen species incorporated into the metal hydroxide layer [44]. The latter species contributes to the underpotential electrooxidation of $\mathrm{Ni}$ (II) hydroxide, yielding $\mathrm{Ni}$ (III) species and inserted hydroxyl ion as indicated by the following equilibrium:

$\mathrm{Ni}^{2+}($ film $)+(\mathrm{OH})_{i} \rightleftarrows \mathrm{Ni}^{3+}($ film $)+\left(\mathrm{OH}^{-}\right)_{i}$

Therefore, the complete conversion of $\mathrm{Ni}$ (II) into $\mathrm{Ni}$ (III) should take place at a potential lower than the threshold potential corresponding to the activity of hydrous nickel hydroxide in the co-precipitated hydroxide electrode. In that case the overall anodic process approaches the reversible behaviour described by reaction (1). On the other hand, reaction (3) occurs in the reverse direction as a catalytic electrochemical process in hydrous nickel hydroxide [43]. Furthermore, the sequence of reactions (1)-(3) depends on the quantity of hydroxyl ions inserted into the metal hydroxide layer. Under comparable preparation conditions of the metal hydroxide layer, thin layers are found to be the most effective for these reactions.

The explanation discussed above is consistent with the fact that $\mathrm{OH}^{-}$ion insertion is facilitated by its electrochemical adsorption on $\mathrm{Co}$ (III) species, as has already been reported for $\mathrm{Co}_{3} \mathrm{O}_{4}$ [45], and the $\mathrm{Ni}$ (III) species probably stabilizes the trapped $\mathrm{OH}$ species. The electro-oxidation of inserted $\mathrm{OH}^{-}$ions can be represented by the reaction:

$2\left(\mathrm{OH}^{-}\right)=\left(\mathrm{H}_{2} \mathrm{O}_{2}^{-}\right)+e$

while the electroreduction of $\mathrm{OH}$ species within the metal hydroxide layer should occur in the presence of molecular oxygen [44] according to:

$2(\mathrm{OH})+\mathrm{O}_{2}+2 e^{-}=2 \mathrm{O}_{2} \mathrm{H}^{-}$

This reaction indicates that the $\mathrm{O}_{2} \mathrm{H}^{-}$ion in base can be formed by an outer-sphere electron transfer as it occurs for superoxide ion formation on graphite in alkaline solutions.

The electrochemical behaviour of electrodes made up of alternate hydroxide layers depends on the distribution of the different layers, and on the nature of the inner layer in direct contact with the conducting substrate. In any case, the rest potential of the electroreduced metal hydroxide layer approachs that of the $\mathrm{Co}$ (II)/Co(III) redox couple, while the rest potential of the electrooxidized layer is 
determined by the $\mathrm{Ni}(\mathrm{II}) / \mathrm{Ni}(\mathrm{III})$ redox couple. Despite this interesting time dependence of the open circuit potential, these results involve some uncertainty about the actual distribution of the supposed homogeneous metal hydroxide layers. In this case, after long-term potential cycling, the voltammograms of this type of electrode approach that of co-precipitated hydroxide electrodes due to interpenetration of the hydrous hydroxide layers. Nevertheless, when the initial inner layer corresponds to hydrous cobalt hydroxide, the characteristics of the substrate in the hydrogen adatom potential range are influenced by the formation of a scarcely electroreducible species. This is in agreement with the structure change of $\mathrm{Co}(\mathrm{OH})_{2}$ in base produced during cycling [16] in the -0.80 to $0.65 \mathrm{~V}$ potential range, which produces a $\mathrm{CoO}$ inner layer in direct contact with the platinum substrate. Hence, the change in the nature of the electrode accounts for the tendency of the platinum hydrogen adatom characteristics to disappear.

\section{ACKNOWLEDGEMENTS}

INIFTA is sponsored by the Consejo Nacional de Investigaciones Cientificas y Técnicas, the Universidad Nacional de La Plata and the Comisión de Investigaciones Científicas (Provincia de Buenos Aires). M.E.F. participated in this work on leave of absence from the Universidad Nacional de Tucumán, supported by a grant from the Consejo de Rectores de Universidades Nacionales of Argentina.

\section{REFERENCES}

I M. Sakashita and N. Sato, Corrosion, 35 (1979) 351.

2 E. Matijevic, Corrosion, 35 (1979) 264.

3 M. Cohen, D. Mitchell and K. Hashimoto, J. Electrochem. Soc., 126 (1979) 442.

4 M.M. Lohrengel, P.K. Richter and J.W. Schultze, Ber. Bunsenges. Phys. Chem., 83 (1979) 490.

5 U. Stimming and J.W. Schultze, Electrochim. Acta, 24 (1979) 859.

6 M.M. Lohrengel, K. Schubert and J.W. Schultze, Werkst. Korros., 32 (1981) 13.

7 U. Stimming, J. Electroanal, Chem., 136 (1982) 345.

8 L.D. Burke and O.J. Murphy, J. Electroanal. Chem., 109 (1980) 379.

9 L.D. Burke and D.P. Whelan, J. Electroanal. Chem., 109 (1980) 385.

10 L.D. Burke, M.E. Lyons and O.J. Murphy, J. Electroanal. Chem., 132 (1982) 247.

11 R.S. Schrebler Guzmán, J.R. Vilche and A.J. Arvía, J. Appl. Electrochem. 8 (1978) 67; 9 (1979) 183, 321.

12 R.S. Schrebler Guzmán, J.R. Vilche and A.J. Arvia, Corros. Sci., 18 (1978) 765.

13 H. Gomez Meier, J.R. Vilche and A.J. Arvía, J. Appl. Electrochem., 10 (1980) 611.

14 M.E. Folquer, J.R. Vilche and A.J. Arvía, J. Electrochem. Soc., 127 (1980) 2634.

15 V.A. Macagno, J.R. Vilche and A.J. Arvia, J. Appl. Electrochem., 11 (1981) 417.

16 H. Gomez Meier, J.R. Vilche and A.J. Arvia, J. Electroanal. Chem., 134 (1982) 251; 138 (1982) 367.

17 V.A. Macagno, J.R. Vilche and A.J. Arvia, J. Electrochem. Soc., 129 (1982) 301.

18 L.M. Gassa, J.R. Vilche and A.J. Arvía, J. Appl. Electrochem., 13 (1983) 135.

19 P.C. Milner and U.B. Thomas in C.W. Tobias (cd.), Advances in Electrochemistry and Electrochemical Engineering, Vol 5, Interscience, New York, 1967, pp. 1-86.

20 S.V. Falk and A.J. Salkind, Alkaline Storage Batteries, Wiley, New York, 1969.

21 G.W.D. Briggs in H.R. Thirsk (Ed.). Electrochemistry. Vol. 4. The Chemical Society, London. 1974. p. 33. 
22 A.C.C. Tseung and S. Jasem, Electrochim. Acta, 22 (1977) 31; A.C.C. Tseung, S. Jasem and M.N. Mabmood in S. Srinivasan, F.J. Salzano and A.R. Landgrebe (Eds.), Industrial Water Electrolysis, Softbound Proceedings Series, The Electrochemical Socicty, Princeton, 1978, p. 461.

23 M.R. Tarasevich and B.N. Efremov in S. Trasatti, Electrodes of Conductive Metallic Oxides, Part A, Elsevier, Amsterdam, 1980, pp. 221-259.

24 J. Fischer, H. Hofmann, G. Luft and H. Wendt, Chem.-Ing.-Tech., 52 (1980) 438.

25 J. McBreen in J.O'M. Bockris, B.E. Conway, E. Yeager and R.E. White (Eds.), Comprehensive Treatise of Electrochemistry, Vol. 3, Plenum Press, New York, 1981, pp. 303-340.

26 D.E. Hall, J. Electrochem. Soc., 130 (1983) 317.

27 R.G. Gunther and S. Gross, (Eds.), The Nickel Electrode, The Electrochemical Society, Pennington, 1982.

28 K. Sugita and S. Ohkuma, Denki Kagaku, 41 (1973) 440.

29 I.S. Shamina, O.G. Maladin, S.M. Kakhovskaya and L.A. Vereshchagina, Elektrokhimiya, 10 (1974) 1571.

30 I.S. Shamina, O.G. Maladin, S.M. Rakhovskaya, L.N. Sal'kova, A.V. Vasev and L.A. Vereshchagina, Elcktrokhimiya, 12 (1976) 573.

31 H. Yasuda, K. Twai and G. Takeshima, G.S. News Tech. Rep., 36 (1977) 103.

32 O.G. Maladin, A.V. Vasev, P.N. Bityutskii, I.S. Shamina and G.V. Suchkova, Elektrokhimiya, 14 (1978) 91.

33 A.M. Trunov, A.I. Kotseruba, N.M. Yakovleva and V.E. Polishchuk, Elektrokhimiya, 14 (1978) 1165.

34 D.F. Pickett and J.P. Maloy, J. Electrochem. Soc., 125 (1978) 1026.

35 O.G. Maladin, I.K. Kuchkaeva, A.V. Vasev, P.N. Bityutskii, L.A. Vereshchagina, and G.V. Suchkova, Elektrokhimiya, 14 (1978) 1380.

36 O.G. Maladin, S.M. Rakhovskaya, A.V. Vasev, L.A. Vereshchagina and G.V. Suchkova, Elektrokhimiya, 16 (1980) 1041.

37 D.H. Fritts, J. Power Sources, 6 (1981) 171, 327.

38 M.E. Folquer, J.R. Vilche and A.J. Arvia, Anal. Asoc. Quím. Arg., 70 (1982) 873.

39 D.H. Fritts, J. Electrochem. Soc., 129 (1982) 118.

$40 \mathrm{~S}$. Trasatti and G. Lodi in S. Trasatti (Ed.), Electrodes of Conductive Metallic Oxides, Elsevier, Amsterdam, 1981, p. 521.

41 A. Carugati, G. Lodi and S. Trasatti, J. Electroanal. Chem., 143 (1983) 419.

42 L.D. Burke, M.E. Lyons, F.I.M. O'Sullivan and D.P. Whelan, J. Flectroanal. Chem., 122 (1981) 403

43 R.E. Carbonio, V.A. Macagno and A.J. Arvía, J. Electronanal. Chem., 147 (1983) 139.

44 R.E. Carbonio, V.A. Macagno and A.J. Arvía, J. Electronanal. Chem., submitted.

45 B.N. Efremov, G.I. Zakharkin, S.R. Zhukov and M.R. Tarasevich, Elektrokhimiya, 14 (1978) 937. 